\title{
ENFERMEDAD Y METÁFORA
}

\author{
LUIS FERNANDO CARDONA SUÁREZ
}

Pontificia Universidad Javeriana

\begin{abstract}
RESUMEN: En el presente texto abordamos a la luz de la antropología filosófica la pregunta por nuestra experiencia de la enfermedad. Como seres dotados de palabra, esta experiencia está mediada siempre por nuestra manera de hablar sobre ella. El poder nombrar lo que nos pasa nos configura como individuos orgánicos peculiares, frente a otras formas de vida. Pero al hablar sobre nuestras enfermedades caemos en una profunda paradoja: tenemos la necesidad de comunicar a otros nuestra vivencia, que es algo tan íntimo y privado que individualiza; de otra parte, la comprensión de los otros de lo que nos pasa encuentra, sin embargo, un límite casi infranqueable. A menudo, este límite suele ser bordeado por la metáfora y su lenguaje traslaticio. Queremos examinar, a continuación, la relación que podemos establecer entre enfermedad, dolor y metáfora.
\end{abstract}

PALABRAS CLAVES: antropología filosófica; enfermedad; dolor; metáfora; Ozick; Sontag; Mukherjee; Canguilhem; Blumenberg.

\section{Illness and Metaphor}

ABSTRACT: In the present text we approach the question of our experience of illness and pain in the light of philosophical anthropology. As beings endowed with words, this experience is always mediated by our way of speaking about it. The power to name what happens to us configures us as peculiar organic individuals, compared to other forms of life. But when talking about our pains and illnesses we fall into a profound paradox: we have the need to communicate our pain to others, which is something so intimate and private that it individualizes; on the other hand, the understanding of the others of our experience finds, however, an almost insurmountable limit. Often, this limit is usually bordered by metaphor and its translative language. We want to examine, next, the relationship that we can establish between illness, pain and metaphor.

KEY WORDS: philosophical anthropology; disease; pain; metaphor; Ozick; Sontag; Mukherjee; Canguilhem; Blumenberg.

A continuación, queremos señalar, a modo de ejemplo, a partir de la experiencia concreta de tres escritores, Cynthia Ozick, Susan Sontag y Siddhartha Mukherjee, cómo se articula en sus obras, más allá de sus características particulares, la vivencia de la enfermedad y las posibilidades de la metáfora para indicar la vulnerabilidad que constituye nuestro modo de ser. En un segundo momento, examinamos el límite del discurso médico para dar cuenta de la vivencia de la enfermedad y el dolor. Retomamos aquí los trabajos del médico y filósofo de la ciencia Georges Canguilhem, que ha mostrado cómo la comprensión de la enfermedad determina el límite y las posibilidades, en sentido kantiano, de la medicina como ciencia en el mundo contemporáneo. Siguiendo su divisa fundamental según la cual el pathos condiciona al logos, mostramos cómo la patología paradójica del hombre normal permite acercarnos de manera concreta a las preguntas fundamentales que una antropología filosófica debe asumir, cuando quiere atender a la experiencia de la enfermedad y el dolor. Finalmente, en un tercer momento, queremos indicar la articulación que podemos encontrar entre la patología paradójica de Canguilhem y la antropología metaforológica de 
Hans Blumenberg. Esta articulación la queremos resaltar, aunque sean escasas las alusiones directas entre ambos pensadores. Sostenemos aquí que la divisa metodológica de la patología paradójica de Canguilhem puede encontrar su anclaje antropológico en los análisis blumenberguianos de la metáfora náutica de la existencia humana.

En el presente artículo la metáfora no está tomada simplemente como un modo de conocer, sino también de ser. Ella nos indica cómo asumir y comunicar nuestra cruda vivencia de la enfermedad y el dolor. Esta vivencia está atravesada por el fenómeno de la delegación, que caracteriza a toda forma de lenguaje traslaticio. Así, podemos entender por qué Ozick, Sontag y Mukherjee consideran que cuando hablamos de manera concernida sobre la experiencia de nuestras enfermedades y dolencias desplegamos en comunidad una acción ética e incluso política. Pero debemos reconocer también que no podemos disolver la paradoja que atraviesa la experiencia humana de estas vivencias, pues si bien tenemos la necesidad de comunicar a otros lo que nos pasa, que es algo tan íntimo y privado que nos individualiza, su comprensión encuentra un límite, ya que el otro, aunque comprenda, no puede sentir lo que se siente en primera persona.

\section{Hablar de NUESTRA eXPERIENCIA DE LA ENFERMEDAD Y EL DOLOR}

La escritora norteamericana de origen judío Cynthia Ozick fue invitada como conferencista principal a un congreso de medicina. Sin duda, era una invitación inusual. En este tipo de eventos se suele hablar sobre temas referidos a la práctica o a la teoría médica. Por ejemplo, presentar el avance en la investigación científica en alguno de sus campos de especialización; el desarrollo de una novedosa forma de intervención terapéutica o farmacológica para alguna patología que tiene un gran impacto social; la delimitación metodológica o conceptual de la investigación clínica o básica; o, en términos más generales, señalar el impacto de este saber a lo largo de la historia de la humanidad y de modo particular en el mundo contemporáneo. Por esta razón, la escritora tenía que escoger un tema que fuese adecuado a la ocasión.

Su decisión fue, obviamente, la más acertada. Escogió como tema central de su intervención la metáfora. Con esta decisión quería, por un lado, abrir el diálogo entre el saber médico y el fino trabajo de la palabra; y por el otro, atender a tres tópicos que a todos nos inquietan. Se proponía así tejer un puente entre su experiencia más íntima de sufrimiento, el trabajo paciente de la escritura y la dimensión terapéutica de este ejercicio, cuando se vincula con la memoria. Estos tres tópicos, la reflexión concernida, la elaboración de la experiencia en la palabra y lo curativo del oficio de escribir, son articulados en su consideración en torno a la metáfora. La escritora buscaba así mostrar la relación que la metáfora tiene con la práctica médica y la experiencia del sufrimiento.

Obviamente, la metáfora no está aquí abordada en su sentido más elemental, a saber, como el «dar a una cosa el nombre de otra» (Aristóteles, Poética, 
1457b). Ozick se distancia también de las consideraciones epistemológicas y puramente estilísticas de la metáfora y se concentra en resaltar su dimensión moral. Esta dimensión la encuentra en la relación entre metáfora y memoria. $\mathrm{Al}$ detenerse en esta relación, la escritora quiere ubicar la metáfora no en el campo de la mera inspiración, sino en el de la comprensión, es decir, la asume como una hermenéutica de la propia existencia ${ }^{1}$, ya que "cuanto más serios somos en la vida menos podemos prescindir de ella» (Ozick, 2016, 64).

En este sentido, la metáfora nos permite transformar «lo extraño en lo familiar» (Ozick, 2016, 80). Y como tal ella reposa en una experiencia anterior ${ }^{2}$, pues indica siempre aquello que perturba al individuo en su intercambio psicosomático con un medio exterior. Esta reducción se convierte en una especie de trabajo sacerdotal de interpretación. Esta reducción también la ha indicado Canguilhelm (2004), cuando señala que la salud no es propiamente un concepto científico demostrable, sino uno vulgar anclado en un cierto sentimiento de bienestar, en la medida en que «está al alcance de todos» $(52)^{3}$.

1 Recordando que la inspiración puede terminar en la ensoñación o en la fantasía, pero teniendo siempre su origen en el terror, Ozick evoca el festival ateniense de las Antesterias, donde los devotos a Dionisio buscaban en las fiestas de las flores ahuyentar a los espíritus. Y en el culto a los misterios eleusinos los devotos, que se sometían a la inmersión en las aguas del río del olvido, bebían una pócima sagrada y proclamaban el nacimiento de un niño santo. En estas fiestas la función sacerdotal no era simplemente una actividad intelectual, sino que tenía una dimensión ciertamente política, ya que «los sacerdotes tenían que ocuparse de la interpretación» (Ozick, 2016, 68), para ponerla al servicio de la comunidad. Asumimos aquí esta función de interpretación como una hermenéutica de la existencia, en la medida en que lleva consigo «la concentración de la experiencia»(Ozick, 2016, 83). Ese poder «entender lo incomprensible y, sobre todo, entender lo que quiere ser entendido, compromete la totalidad de nuestra capacidad de meditar, que siempre encuentra en las religiones, en el arte de los pueblos, en el torrente de nuestra tradición nuevas respuestas y, junto con cada nueva respuesta, una nueva pregunta. En eso consiste la hermenéutica como filosofía» (GADAMER, 2011, 181). Aquí esta hermenéutica la bosquejaremos a partir de la lectura de la función antropológica de la metáfora, siguiendo en este punto al filósofo alemán Hans Blumenberg.

${ }_{2}$ Ozick resalta que este trabajo de reducción es una nota característica del pueblo judío que, por ejemplo, recordó el tiempo de cautiverio en Egipto, no como una forma de rencor, sino para nunca olvidar que el extraño debe ser acogido de la misma manera que el amigo. Esta reducción antes de encerrarse en el pasado abre de manera curativa el porvenir. Así pues, la memoria se convirtió en una especie de piedad frente al extranjero. Con este recuerdo la escritora quiere resaltar la particular afinidad que tiene el pueblo judío con la metáfora y su relación con la memoria. Para ella, la metáfora está aquí asumida como memoria del dolor del destierro. Por esta razón, Ozick señala que esta piedad frente al extranjero es una suerte de «imaginación de la reciprocidad» (Ozick 2016, 75), resaltando con ello la dimensión ética que tiene la metáfora.

3 En El conflicto de las facultades, Kant señala que la salud es propiamente un sentimiento y no un dato que puede ser demostrado científicamente, pues «uno puede sentirse sano (a juzgar por el sentimiento placentero de su vida), mas nunca se puede saber que uno está sano. Toda causa de muerte natural supone una enfermedad, se la sienta o no. [...] La ausencia de tal sentimiento [de estar enfermo] no expresa respecto a la buena salud del hombre nada más que hallarse aparentemente sano» (179-180; Ak. VII. 100). Lo decisivo en nuestra condición con respecto a la salud o a la falta de ella es pues siempre el 
Obviamente, en este trabajo se busca evitar caer en los giros de la abstracción, propios del pensamiento especulativo, para atender más bien a lo concreto. Ya sea éste un presente que nos oprime con dolor o terror o un pasado que se ha convertido en un trauma íntimo que nos demanda llevarlo a la memoria. El trabajo de la metáfora no es pensado aquí como un ejercicio artificial anclado en la pura inspiración, pues en ésta no hay lugar para la memoria.

Cuando atendemos a lo concreto, podemos concentrarnos en todo aquello que nos afecta y a la vez abrirnos a los dolores de los otros. Por tanto, en «esta concentración metafórica los médicos pueden imaginar cómo se sienten sus pacientes. Quienes no sienten dolor pueden imaginar a quienes lo padecen. Quienes ocupan el centro pueden imaginar a quienes están fuera de él. Los fuertes pueden imaginar a los débiles. Las vidas iluminadas pueden imaginar a las oscuras» (Ozick, 2016, 83-84). Con estas palabras finales Ozick exhorta a los médicos a no perder de vista en el trato con el dolor la trama interna de metáfora y memoria. De esta manera, la escritora busca indicar la pertinencia de su consideración sobre la dimensión moral de la metáfora para abordar los asuntos propios de la práctica médica. Pero esta indicación quiere confrontar, igualmente, aquel malabarismo de ciertos poetas contemporáneos que, en la celebración de su singularidad ${ }^{4}$, no permiten que "el dolor de un corazón implique la comprensión de otro corazón» (Ozick, 2016, 82). En estos malabarismos no encontramos una esperanza de regeneración o sanación. Para Ozick, esta esperanza es la que se abre en la relación entre metáfora y memoria.

Encarando sus dolores y temores más íntimos como paciente de cáncer de mama, la escritora norteamericana Susan Sontag asume también el tema de la metáfora como objeto de su reflexión concernida. Su análisis se centra ahora en la relación entre metáfora y enfermedad. En sus famosos ensayos La enfermedad y sus metáforas de 1978 y el Sida y sus metáforas de 1988, Sontag quiere denunciar que ciertas enfermedades, en un primer momento el cáncer y posteriormente el Sida, están unidas en el mundo contemporáneo, de un modo particular, a metáforas. Se trata ante todo de aquellas que provienen de la guerra. En la mayoría de los casos esta unión es fuente de nuevos dolores diferentes a los que trae consigo el padecimiento de la enfermedad. Por ejemplo, se incrementa la

modo como nos sentimos; en este sentido, no podemos pasar por alto esta sensación que marca nuestra actitud frente a la vida. Siguiendo la distinción kantiana entre conceptos escolásticos y cósmicos, Canguilhem señala que el concepto de norma es justamente un concepto escolástico, mientras que el de normal es cósmico. En este sentido, «es posible que lo normal sea [, al igual que sucede con la salud] una categoría del juicio popular, porque su situación social es vivamente, aunque de un modo confuso, sentida por el pueblo como no siendo recta» (CANGUILHEM, 2011, 185).

4 Como lo señala Ozick en una nota a pie, ella se refiere aquí a un tipo de poesía seducida por una especie de "furor délfico», que se entrega a la autonomía pura del acto creador en cuanto mero efecto de una máquina de lenguaje, que nada tiene que ver con la crítica de la vida, pues simplemente se entrega «a lo exquisitamente autónomo» (Ozick, 2016, 82). Esta entrega es propia tanto de la exacerbación del nihilismo como de los malabares de la deconstrucción que terminan en la pérdida del yo y del texto. 
soledad, el aislamiento y la exclusión social, al vincular ciertas patologías a una idea fuerte de responsabilidad psíquica o moral del que las sufre ${ }^{5}$.

El análisis histórico cultural que la escritora emprende en estos ensayos tiene como punto de partida el reconocimiento de que todos poseemos, como seres humanos, una doble ciudadanía: la pertenencia al mundo de los sanos y al de los enfermos (Sontag, 2017, 11) . En el primero nos sentimos cómodos y deseamos, por ello, permanecer siempre en él sin perturbación alguna; al contrario, en el segundo se incrementan nuestras inseguridades, sospechas y dudas. Aunque quisiéramos vivir eternamente en el primero, tarde o temprano nos vemos abocados a reconocernos también como ciudadanos del segundo. Ésta es pues una condición que no podemos subestimar o simplemente desconocer. El paso del primer mundo al segundo es, por tanto, tan inevitable como inquietante, ya que es fuente de pavor por todo aquello que trae consigo, el deterioro de nuestras fuerzas vitales, la pérdida de nuestra querida autonomía ${ }^{7}$, el inevitable envejecimiento ${ }^{8}$ y, finalmente, la muerte. Por esta razón, se suele

5 Pero debemos tener aquí en cuenta que hoy la enfermedad no tiene ya ninguna relación con una responsabilidad individual fuerte: «Los seres vivos que somos son efecto de las propias leyes de la multiplicación de la vida; los enfermos que somos son efecto de la panmixia, del amor y del azar. Todo esto hace que seamos únicos, como a menudo se lo ha escrito para consolarnos por ser el producto de bolillas sorteadas en la urna de la herencia mendeliana. Únicos, por cierto, pero también a veces mal venidos» (CANGUILHEM, 2011, 224).

6 Esta idea de la doble ciudadanía se encuentra también presente en Kant en los siguientes términos: "Dos cosas colman el ánimo con una admiración y una veneración siempre renovada y creciente, cuanto más frecuente y continuadamente reflexionamos sobre ellas: el cielo estrellado sobre mí y la ley moral dentro de mí. Ambas cosas no debo buscarlas ni limitarme a conjeturarlas, como si estuvieran ocultas entre tinieblas, o tan en lontananza que se hallaran fuera de mi horizonte; yo las veo ante mí y las relaciono inmediatamente con la conciencia de mi existir» (Crítica de la razón práctica, A288-A289). En este sentido, somos habitantes de dos reinos, el de los fenómenos y el noumenal.

7 La tan querida autonomía es realmente un bien escaso y voluble. En efecto, en la experiencia de la enfermedad descubrimos que nuestra vida se ve alterada de tal manera que podemos incluso llegar a perder nuestra capacidad de deliberar sobre el tratamiento a seguir, comprender sus implicaciones o simplemente entender la situación en la que nos encontramos, debido a la alteración vital por la que estamos pasando. Aunque solemos decir que la salud es el silencio de los órganos (CANGuilhem, 2009, 166-182), debemos reconocer también que la enfermedad emerge como una cierta interferencia entre el cuerpo y el espíritu. Para un enfermo, «su cuerpo le molesta, se ha convertido en un obstáculo para su actividad autónoma, para su deseo de perseguir los objetivos que se había propuesto. Más profundamente aún que la pérdida de control de su cuerpo, la enfermedad designa en estado de una "humanidad herida", de una persona cuya capacidad fundamental para manejar su propia vulnerabilidad se halla comprometida. Su autonomía ha sido quebrada» (Pelluchon, 2013, 64).

8 La experiencia dolorosa de la vejez se ha incrementado con el paso del tiempo y con el vertiginoso aceleramiento cultural propio del mundo contemporáneo. Incluso, «la fabricación de viejos es deliberada: se debe a los progresos de la medicina, a la desaparición de la mortalidad infantil y juvenil, a un trabajo menos duro, a las vacaciones remuneradas, a la ausencia de guerras durante décadas, a la seguridad social y a la institución de una pensión de jubilación suficiente para vivir y cuidar su salud. [Hay entonces] una fábrica 
vincular la palabra cáncer con la muerte y el que se identifica con esta afección patológica cae con frecuencia en un profundo abatimiento espiritual. Para enfrentar la identificación simple de cáncer y muerte, Sontag se propone en su famoso ensayo desmitificar esta enfermedad.

En la mitología popular del siglo XIX la tuberculosis fue asumida como una enfermedad de la pasión, que individualizaba y convertía al que la sufría en una persona «interesante» (Sontag, 2017, 41). En el siglo XX el cáncer se convierte en la metáfora de la "patología extrema» (Sontag, 2017, 100), ya que expresa una alteración interna de las formas del crecimiento, a nivel celular, que sigue un patrón anormal, medible, incesante, constante y, en última instancia, letal. No se trata pues de una patología que envuelve a su víctima en una melancolía extrema, como ocurría antes con la tuberculosis, sino de una enfermedad que consume al cuerpo, justamente en el propio principio de su crecimiento. Esto

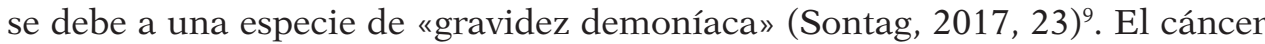
es pues sinónimo de un cuerpo que se está consumiendo en sí mismo.

El que padece esta enfermedad teme a los inmensos dolores, que trae este proceso de consunción de su propio cuerpo, y a su vez a los innombrables sufrimientos que generan los tratamientos para combatirla. A menudo estos padecimientos hunden a los enfermos en un aislamiento y desesperación inconmensurable, donde se ve realmente limitada la posibilidad de compañía y comprensión. Con frecuencia, el paciente se queda irremediablemente solo encarando su condición, aunque en la historia del tratamiento del cáncer un lugar muy importante lo ocupa la promoción de asociaciones de enfermos que luchan por mejoras en los tratamientos, buscando así que estas posibilidades sean regidas por criterios de justicia, inclusión y equidad. Por esta razón, la experiencia y el tratamiento de esta enfermedad adquieren en el siglo XX una dimensión más allá de lo individual, en la medida en que permean la sociedad entera, incluso en el plano político ${ }^{10}$. En su tratamiento se exige así una gran movilización de todas las energías vitales ${ }^{11}$, tanto en el plano

dedicada colectivamente a producir viejos» (REDEKER, 2017, 26-27). Pero, paradójicamente, nuestra cultura no está dispuesta a asumir las consecuencias éticas y políticas que esto trae consigo. Esto se puede ver, de manera particular, en el fenómeno reciente de la declaración de la emergencia sanitaria a nivel global a causa de la pandemia generada por el COVID-19.

9 El cáncer se nos presenta culturalmente como el doble invertido (Doppelgänger) de nosotros mismos, pues «si la inmoralidad es nuestra aspiración, también lo es, en un sentido bastante perverso, la de la célula cancerosa» (MukHerJeE, 2014, 27).

10 En el debate contemporáneo sobre la enfermedad un lugar importante lo ocupa la búsqueda de modelos de atención médica más humanos; en estos modelos se pone al orden del día la discusión sobre la articulación entre la responsabilidad ética en la atención clínica, la ética del cuidado y de la organización del sector de la salud, tanto a nivel público como privado (Dupuis, 2014).

11 Como si se tratará de una verdadera guerra el cáncer ha desplegado en el siglo XX una movilización total en el sentido de Jünger, pues «al crecer el sentimiento de que el ámbito vital en su conjunto se halla cuestionado y amenazado crece también la necesidad sentida por el hombre de volverse hacia una dimensión que lo sustraiga al dominio ilimitado del 
del saber científico como en el de la comprensión social de su presencia devastadora.

En sus ensayos Sontag se une a esta movilización para denunciar, con una actitud claramente militante, que las metáforas adheridas a nuestra comprensión social de una enfermedad, como el cáncer o el sida, están particularmente impregnadas de un vocabulario militar y de guerra ${ }^{12}$. Las metáforas de guerra aparecieron en la medicina alrededor de 1880, cuando se descubrió que las bacterias invadían al cuerpo y lo infiltraban (Sontag, 2017, 79). Más tarde la enfermedad se convirtió en un enemigo contra el cual debía levantarse la sociedad entera para combatirlo, ya sea reduciéndolo a su mínima expresión o, por lo menos, neutralizando sus efectos devastadores, tanto a nivel individual como colectivo.

En su reflexión sobre la enfermedad Sontag se propone exorcizar el poder de seducción del pensamiento metafórico. Para esto, señala cómo al abordar toda enfermedad devastadora, buscamos señalar a la vez los dispositivos inmunológicos para encarar nuestras afecciones y dolencias en lo corporal, lo moral y lo mental: "Gracias a la evolución del lenguaje terapéutico y a la sustitución de metáforas militares por metáforas sobre "las defensas naturales" del cuerpo (en vez de "sistema inmunodefensivo", "capacidad inmunológica del cuerpo", por ejemplo, para terminar de una vez con la jerga militar), el cáncer se librará en parte de sus mitos; y entonces sí podrán hacerse comparaciones con el cáncer sin que ello implique diagnósticos mortales, ni llamadas a las armas a ultranza contra un enemigo letal e insidioso» (Sontag, 2017, 101).

dolor y a su vigencia universal» (JüNGER, 1995, 22-24). Con este crecimiento se justifica la comúnmente llamada guerra contra el cáncer, que moviliza recursos económicos, técnicos, científicos, políticos e incluso emocionales. Por ejemplo, después de la Segunda Guerra Mundial se emprendió una especie de Proyecto Manhattan para luchar contra el cáncer: «La palabra guerra captaba la esencia de la campaña anticáncer. Las guerras exigen combatientes, armas, soldados, heridos, supervivientes, espectadores, colaboradores, estrategas, centinelas, victorias, y no era difícil encontrar un análogo metafórico para cada una de estas palabras también en esa guerra. Las guerras demandan asimismo una definición clara del enemigo. Dan forma incluso a los adversarios informes. De modo que el cáncer, una enfermedad polimorfa de colosal diversidad, se reformuló como una única entidad monolítica. Era una enfermedad» (MuKHERJEe, 2014, 215).

12 Normalmente, se suele decir que los tumores malignos invaden, pues las células cancerosas colonizan zonas del cuerpo, ya sean cercanas o distantes del lugar de su invasión originaria. Igualmente, se indica que debido a una invasión tumoral las defensas del organismo se debilitan o que llegan, incluso, a extinguirse. También su tratamiento está marcado por el vocabulario militar y de guerra. Por ejemplo, «la radioterapia usa las metáforas de la guerra área: se "bombardea" al paciente con rayos tóxicos. Y la quimioterapia es una guerra química, en la que se utilizan venenos. El tratamiento apunta a "matar" las células cancerosas (dentro de lo posible sin matar al paciente). Los efectos secundarios del tratamiento reciben mucha - demasiada- publicidad. (Frase corriente: "el suplicio de la quimioterapia"). Es imposible no dañar o destruir células sanas (por cierto, ciertos métodos contra el cáncer suelen ser cancerígenos), pero se considera justificado casi cualquier daño acarreado al cuerpo, si con ello se consigue salvar la vida del paciente. A menudo, claro está, no se consigue. (Recuérdese: "Tuvimos que destruir Ben Suc para salvarlo"). Todo está; lo único que falta es el recuento de muertos» (SonTAG, 2017, 78-79). 
Sin duda, este desplazamiento no sólo implica la defensa del derecho de los pacientes a recibir tratamientos con equidad y que todos puedan acceder a ellos, ya sea que se trate de procedimientos comprobados en protocolos estandarizados o estén aún en fase experimental. Se requiere contar con la adecuada información sobre las consecuencias y posibilidades de los procedimientos a los que se deben someter los enfermos. Igualmente, esto conduce a una depuración constante de las metáforas que usamos para comprender lo que nos pasa, cuando sufrimos una enfermedad como el cáncer, ya que «nosotros - la medicina, la sociedad - no estamos autorizados para defendernos de cualquier manera que se nos ocurra» (Sontag, 2017, 205).

Después de terminar su residencia en el Instituto del Cáncer Dana-Farber y en el Hospital General de Massachusetts en Boston, el hematólogo y escritor norteamericano de origen indio Siddhartha Mukherjee se propuso comprender el cáncer como una enfermedad que no sólo afecta nuestro cuerpo, sino que desafía también a la sociedad entera en su afán de erigir un mundo sin sufrimiento, lleno de plenitud vital. Para realizar esta tarea, Mukherjee no quiso simplemente emprender una «historia del cáncer», sino más bien narrar su biografía. Es decir, penetrar en el decurso más íntimo de esta patología, para así «desmitificar su comportamiento» (Mukherjee, 2014, 17). Muchas son las preguntas que han surgido frente a esta enfermedad, que suele ser asumida socialmente como "el emperador de todos los males, el rey de los terrores» (Mukherjee, 2014, 18). Por ejemplo, se quiere saber sobre su naturaleza, descubrir una cura definitiva, indagar sus causas y orígenes más remotos, investigar sobre la relación entre esta patología y la dinámica interna de la vida y determinar así sus posibles efectos en nuestras expectativas vitales.

Estas preguntas las abordan tanto los médicos dedicados a la investigación clínica y tratamiento como los pacientes y las familias que los acompañan en su historia de sufrimiento y dolor. En efecto, son cuestiones recurrentes en nuestra experiencia de la enfermedad y del sufrimiento. Si bien hoy sabemos que, en términos generales, el cáncer es una anomalía fisiológica que altera los procesos fisiológicos de las células, trastornando su normal crecimiento, envejecimiento y apoptosis, desconocemos empero la causa de dicha metamorfosis. Ella no sólo afecta a una parte localizada y determinada del cuerpo, sino que se expande a menudo por todo el cuerpo, causando finalmente la muerte del enfermo.

Antes de ser una patología obviamente muy agresiva, cuya causa es aún incierta, pese a la gran investigación adelantada a lo largo del siglo XX para combatirla de múltiples maneras ${ }^{13}$, parece ser que el cáncer está vinculado

13 Si es propio del cáncer el despliegue de una mutabilidad incontrolada, dicha mutabilidad ha acompañado también la historia de su tratamiento. Siguiendo la legendaria figura de la reina persa Atosa, «que envolvía su pecho enfermo en un lienzo para ocultarlo y luego, en un arranque de furia nihilista y presciente, hizo tal vez que un esclavo lo cercenara con un cuchillo» (MukherJee, 2014, 26), podemos entender esta mutabilidad como la metáfora viva de su tratamiento, pues «es una imagen que capta no sólo la capacidad de viajar de la célula cancerosa —-metástasis—, sino también el viaje de Atosa, el largo arco del 
realmente a nuestro genoma. En esta enfermedad «los genes que sueltan las amarras de la división celular normal no son ajenos a nuestro cuerpo, sino versiones mutadas y desfiguradas de los genes mismos que llevan a cabo funciones celulares vitales» (Mukherjee, 2014, 27). Pero el origen de esta mutación es todavía incierto ${ }^{14}$. En este sentido, tenemos que reconocer que la enfermedad y sus innombrables dolores están tejidos a nuestra propia condición vital. No es pues un agente patógeno externo el que produce estos inmensos dolores, sino que la dinámica de nuestra vida los trae consigo. Por esta razón, la comprensión de la enfermedad no puede ser tarea únicamente de un saber especializado y aislado, ya que se requiere un abordaje integral y holístico del individuo biológico así afectado ${ }^{15}$.

Esto nos lleva a asumir que la etiología de una enfermedad supone una concepción de la vida, ya que «la conciencia que los enfermos tienen de su situación nunca es una conciencia desnuda, salvaje. No puede ignorarse la presencia vivida del enfermo, de los efectos de la cultura y la historia» (Canguilhem, 2009, 435). Ahora bien, para combatir de manera definitiva el cáncer, tendríamos pues que poder «liberarnos de los procesos de nuestra fisiología que dependen del crecimiento: envejecimiento, regeneración, curación, reproducción» (Mukherjee, 2014, 551). Obviamente, esta posibilidad es inviable, ya que para lograr este fin tendríamos que dejar de ser aquello que realmente somos: seres vivos con un cuerpo determinado y limitado por su propia constitución. El cáncer define entonces «el límite exterior intrínseco de nuestra supervivencia» (Mukherjee, 2014, 551).

Al penetrar en la biografía de este límite, Mukherjee busca redefinir esta enfermedad que desde Hipócrates se asoció con la imagen de un cangrejo (karninos), enterrado en la arena con las patas extendidas en círculo, y que a

descubrimiento científico e, inmerso en ese viaje, el ánimo, tan ineludiblemente humano, de burlar, perdurar y sobrevivir» (MukHerJeE, 2014, 557). En su dimensión traslaticia la metáfora encarna este ánimo.

14 Aunque a finales del siglo XX la medicina ha dado un paso decisivo para comprender la etiología de un sinnúmero de enfermedades y dolencias, gracias a la investigaciones genéticas, lo cierto es que aún no comprendemos los alcances de estos avances, pues son más las preguntas que se abren que las respuestas que tenemos: "Una cosa es tratar de entender cómo los genes influyen en la identidad, o en la sexualidad, o en el temperamento de los seres humanos, y otra imaginar la posibilidad de cambiar la identidad, la sexualidad o el comportamiento alterando los genes. La primera puede preocupar a los profesores de los departamentos de psicología y a sus colegas de los departamentos vecinos de neurociencia. La segunda, cargada de promesas y peligros, debe preocuparnos a todos» (MUKHERJEE, 2017, 27).

15 Siguiendo a Canguilhem, Lennart Nordenfelt desarrolla un concepto holístico de la salud y de la enfermedad. Según este concepto, «el individuo como sujeto de acción está en el centro de la teoría de la salud, que define a partir de la noción de capacidad (ability). [...] Inscribir [esta] teoría en el seno de una teoría de la acción, [...] permite desplazar la oposición entre normativismo y naturalismo, pero también la tensión entre normas biológicas y normas sociales» (GIRoux, 2011, 133). Este desplazamiento es posible gracias a los aportes metodológicos y conceptuales de la epistemología histórica que son aquí radicalizados en su dimensión holística. 
partir de Galeno se caracterizó como un tumor provocado por «una sobredosis interna de bilis negra» (Mukherjee, 2014, 76). Si bien en griego el término onkos designa «una masa, una carga o, más comúnmente, un peso» (Mukherjee, 2014, 74), es decir, algo que se lleva dentro, Mukherjee resignifica este término, siguiendo el recorrido de su biografía y apelando a la palabra indoeuropea nek, que designa la forma activa del verbo cargar. Así pues, el cáncer no es simplemente un peso o tumor que se soporta.

Si tenemos presente el sentido del término nek, podemos reconocer que con la palabra cáncer queremos significar también «un transportar, mover el peso de un lugar a otro, cargar con algo a través de una larga distancia y llevarlo a un nuevo sitio» (Mukherjee, 2014, 556-557). Con esta resignificación Mukherjee busca atender al carácter metastásico característico de las células cancerosas, que con frecuencia viajan por el cuerpo del enfermo trascendiendo su primera localización más inmediata. Con esto no simplemente se quiere indicar que esta patología sea una metamorfosis del crecimiento normal de las células en un proceso anormal, constante, desenfrenado y sin control, que conduce finalmente a consumir la vida en el cuerpo entero. El cáncer se asemeja también al movimiento propio de la metáfora, a saber, la traslación. Por esta razón, la experiencia de esta enfermedad, con sus innombrables sufrimientos y dolores, ha estado, desde los tiempos de Hipócrates, vinculada en su comprensión a la metáfora.

Al igual que Sontag, Mukherjee busca redefinir las metáforas con las cuales queremos comprender el cáncer. Pero no lo hace ahora con una actitud militante como la de la escritora norteamericana. Más bien, atiende al camino de la biografía, buscando con ello descifrar el enigma que se encierra en esta alteración tan extrema como milenaria, aunque sean aún desconocidas las bases biológicas que la generan ${ }^{16}$. Esta tarea de comprensión tiene también como corolario «redefinir la victoria» (Mukherjee, 2014, 555) que podemos alcanzar en la llamada lucha contra el cáncer. Si bien es legítima la empresa médica de querer erradicar el cáncer de nuestra vida y que incluso podamos reportar casos de pacientes que, gracias a una oportuna intervención terapéutica, se han curado de un cáncer, que se consideraba en un primer momento como letal, no parece que podamos pensar una vida humana sin cáncer o más allá de él. Pero esto no quiere decir que el cáncer pueda ser leído a partir de la imagen cruda del campo de concentración, aunque comparta con él el fenómeno extremo de la aniquilación, en la medida en que «niega la posibilidad de una vida fuera y más allá de sí mismo: subsume todo lo que vive. La vida diaria de un paciente termina por estar tan intensamente ocupada por la enfermedad que el mundo

16 En efecto, pese a los adelantos en genética, «todavía no sabemos, por ejemplo, de qué manera la intersección entre información genética, exposiciones derivadas del comportamiento y accidentes causa hipertensión, esquizofrenia, depresión, obesidad, cáncer o cardiopatías. Encontrar en el genoma los elementos funcionalmente correctos que están vinculados a estas enfermedades es el primer paso hacia el descubrimiento de los mecanismos por los cuales se desarrollan. La comprensión de estos vínculos también revelará el poder predictivo del genoma humano» (MuKherJeE, 2017, 569). 
se desvanece. Hasta el último puñado de energía se gasta en la atención de la enfermedad» (Mukherjee, 2014, 476). Por esto, se hace necesario redefinir el sentido de su tratamiento.

En los tres ejemplos que hemos aquí presentado podemos encontrar las siguientes ideas en común. En la consideración filosófica de la experiencia humana del dolor y de la enfermedad se debe tener en cuenta siempre la experiencia concreta del individuo, del enfermo y del doliente. De lo contrario, la reflexión se enredaría en meras abstracciones. Para atender a esta vivencia la metáfora cumple un papel fundamental. A continuación, queremos examinar estas dos ideas, mostrando cómo podemos ampliar la epistemología histórica desarrollada por el médico y filósofo francés Georges Canguilhem con las ideas fundamentales de la metaforología de Hans Blumenberg ${ }^{17}$.

\section{LA PATOLOGÍA PARADÓJICA DEL HOMBRE NORMAL}

La tarea fundamental de la epistemología histórica de Canguilhem consiste en resaltar que la experiencia humana de la enfermedad solo puede ser comprendida en el horizonte de una filosofía de la vida, donde el centro de la mirada esté puesto en la vivencia concreta del individuo biológico. No se propone pues realizar un análisis epistemológico del saber de la medicina, sino ante todo mostrar su articulación con la historia de una trama vital que le da su sentido. Para esto, Canguilhem saca al debate público los presupuestos filosóficos de las ideas de salud, enfermedad, técnica, terapéutica y anomalía patológica, que subyacen y anticipan el discurso y la práctica médica contemporánea. Ciertas ideas mecanicistas sobre la vida hacen que se olvide la importancia de lo patológico para determinar eso que llamamos vida y que el saber médico busca manipular y ordenar. La tarea de realizar una historia de los conceptos fundamentales de la medicina puede ser leída también como una crítica de la razón médica, en sentido kantiano, ya que busca problematizar los límites de los elementos cognoscitivos de la medicina como productos

17 Ciertamente, nunca se dio un diálogo explicito entre el filósofo e historiador de la medicina Georges Canguilhem (1904-1995), profesor de la Universidad de Estrasburgo y director del Instituto de Historia de las Ciencias, y el filósofo alemán Hans Blumenberg (1920-1996). Pero, siguiendo a Cornelius Borck (2014), podemos señalar que hay profundas coincidencias entre estos dos pensadores de la historia de la ciencia; por ejemplo, ambos consideran que la actividad científica no se puede realizar a espaldas de la historia de los conceptos que han configurado un determinado campo de saber, pues epistemología, historia y ciencia se implican mutuamente. Igualmente, señalan que la historia de un determinado campo científico, por ejemplo, la medicina, puede ser tenida como un caso concreto de indagación filosófica. En este sentido, no podemos desconocer la historia en la que se han tejido prácticas y conceptos para abordar los fenómenos fundamentales de la vida. Obviamente, no podemos pasar por alto las diferencias entre el programa de la epistemología histórica, más centrado en una comprensión holística de las ciencias de la vida, y el de la metaforología centrado en la fenomenología como antropología filosófica o fenomenología del mundo de la vida del hombre (168-195). 
de la ciencia ${ }^{18}$. En este sentido, las dos preguntas que guían el trabajo de la epistemología histórica son: ¿qué puedo conocer de la vida a partir del discurso médico? Y, ¿cuáles son los límites de la razón al conocer la vida?

Lo que podemos conocer de la vida está obviamente mediado por el saber del cuerpo (Canguilhem, 2011, 227), esto es, por la experiencia de todo lo que nos afecta y de las alteraciones que sufrimos en el intercambio con el medio ambiente. Pero este medio no puede ser considerado como una realidad física eterna e inmutable ${ }^{19}$, ya que está también, en su dimensión biológica, mediado y configurado histórica, cultural y socialmente ${ }^{20}$. En este sentido, el individuo

18 Al igual que sucede en Kant, Canguilhem considera que los conceptos que determinan una ciencia no tienen validez por sí mismos fuera del campo de la experiencia. En este sentido no podemos prescindir de la experiencia al momento de querer comprender un determinado campo teórico como sucede en el caso de la patología. Siguiendo así la distinción kantiana que se encuentra en la doctrina trascendental del método entre los conceptos escolásticos (Schulbegriffe), esto es, aquellos que se aprenden en un determinado campo de saber, y los cósmicos (Weltbegriffe), que sirven de fundamento a los primeros (Crítica de la razón pura, B866), Canguilhem sostiene que el concepto de normal, que tiene su campo de determinación en el saber clínico, es realmente un concepto cósmico en sentido kantiano, pues se trata de una «categoría del juicio popular porque su situación social es vivamente, aunque de un modo confuso, sentida por el pueblo como no siendo recta» (CANGUilhem, 185). Y teniendo en cuenta la premisa kantiana de que los conceptos alejados de las intuiciones son vacíos y que, a su vez, las intuiciones sin conceptos ciegas (Crítica de la razón pura, B75), podemos decir igualmente que la condición de posibilidad de aquello que consideramos normativo se identifica con la condición de posibilidad de la experiencia de dichas reglas y medidas. De esta manera, y siguiendo una vez más a Kant, Canguilhem considera que, si bien podemos decir que el bienestar no se siente, en la medida en que es mera conciencia de vivir, y que la salud es, como afirma reiteradamente Leriche, «la vida en el silencio de los órganos», entonces «la inocencia y la salud surgen como los términos de una tan buscada como imposible regresión, en medio del furor de la culpabilidad y el ruido del sufrimiento" (CANGUilHem, 2011, 191).

19 Para Canguilhem, el medio ambiente no es un hecho físico, sino biológico; esto implica que la relación entre organismo y medio debe ser asumida realmente como el efecto de «una actividad propiamente biológica, como la búsqueda de una situación en la cual el ser vivo recoja en lugar de que sufra las influencias y las calidades que responden a tales exigencias, entonces los medios ambientes en los cuales los seres vivos se encuentran ubicados están recortados por ellos. En este sentido, el organismo no se encuentra arrojado en un medio ambiente al cual tiene que plegarse, sino que estructura su medio ambiente al mismo tiempo que desarrolla sus capacidades en cuanto organismo» (CANGUILHEM, 2011, 229).

20 Debido a esta mediación, todo lo que le sucede al cuerpo está afectado también por dicha mediación. Por ejemplo, el dolor no es simplemente una afección de naturaleza psicobiológica, sino ante todo una experiencia. «La medicina despersonaliza el dolor, involuntaria o explícitamente, al envolverlo en la maquinaria de sus proezas de alta tecnología. Le suprime su humanidad retorcida y nos alienta a olvidar que dolor y enfermedad no son lo mismo. La dificultad principal de la entrega total del dolor a la medicina es, sin embargo, que actuamos después como si pudiéramos dejar de pensar en él. El dolor se convierte en otro asunto complejo que dejamos en manos de los especialistas y expertos» (MorRIs, 1993, 201). $\mathrm{Al}$ hacer esto no reconocemos que la experiencia del dolor está siempre tejida histórica y culturalmente. En este sentido, «la historia del dolor remite a la historia de la experiencia, es decir, a la historia de lo que es al mismo tiempo propio y ajeno, de uno y de otros, individual y colectivo» (Moscoso, 2011, 14). 
orgánico no sólo cuenta con un medio, sino que lo configura y altera en su devenir vital. El cuerpo es el lugar y la fuente tanto de la posibilidad como de la afectación.

En su texto de 1943, Ensayo acerca de algunos problemas relativos a lo normal y lo patológico, Canguilhem señala que el componente normativo es una característica común a los conceptos y al cuerpo, y que determina, por tanto, todo lo que ellos pueden hacer, les sucede o acontece. En este sentido, lo normativo delimita aquello que es o no posible en la vida como fenómeno biológico. Por lo tanto, lo que de ordinario se asume como una desviación patológica no es simplemente la mera ausencia de norma, sino una normatividad limitada, una norma de vida inferior que en un momento y situación determinados altera la seguridad biológica con la que inicialmente se contaba. Ahora bien, si se acepta que la enfermedad sigue siendo una especie de norma biológica, se debe reconocer también que «el estado patológico no puede ser denominado "anormal" de un modo absoluto, sino anormal dentro de la relación con una situación determinada» (Canguilhem, 2011, 149) y para un individuo determinado.

Esta delimitación de la negatividad propia de lo patológico permite considerar que la vida es un valor, como lo resaltaba ya antes Nietzsche ${ }^{21}$, porque es frágil, esto es, porque desde un comienzo está atravesada por una estabilidad crítica y paradójica. En efecto, cuando queremos comprender nuestra experiencia particular del sufrimiento, el dolor y la enfermedad, debemos emprender la exigente tarea de realizar una «patología paradójica del hombre normal, mostrando que la conciencia de la normalidad biológica incluye la relación con la enfermedad, el recurso a la enfermedad, como la única piedra de toque que está conciencia reconoce y por tanto exige» (Canguilhem, 2011, 231). No podemos comprender la vida, si no estamos entonces dispuestos a bordear los misterios de la enfermedad y el dolor. Esto implica aceptar que la enfermedad no es una mera alteración de una normatividad previamente dada. Más bien, se trata de la emergencia de una nueva normatividad que envuelve al individuo biológico en otras relaciones con su entorno vital, demandándole a su vez otra comprensión diferente de la vida a la que se había ya habituado ${ }^{22}$.

21 Siguiendo a Nietzsche, Canguilhem considera que lo propio de la vida es la constante obstinación en seguir siendo. En este sentido, la «vida es valor porque es lo que todo ser vivo, desde la bacteria más insignificante hasta los organismos más complejos, buscan y se esfuerzan en mantener: la vida es valor porque es lo que los seres vivos valoran, en tanto no permanecen indiferentes. El valor en sí siempre permanece, pero ello no significa que no cambie de contenido: no siempre se valora lo mismo ni de la misma forma. Las estrategias, que cada ser vivo utiliza para seguir viviendo, son variadas, cambian de agente en agente, y de un momento a otro en el mismo ser. Lo que hace cada ser vivo en cada instante, para seguir viviendo, inaugura una gama infinita y espontánea de formas de lograr tal cometido; cada ser vivo hace frente a otros obstáculos del medio de una manera única y, por qué no decirlo, creativa» (BACARLETT, 2010, 77). Esta valoración ínsita en cada ser vivo es lo que nosotros captamos normalmente como la tendencia de la vida a sobrevivir, pese a los obstáculos y adversidades con las que todo individuo se encuentra.

22 Obviamente, esta patología paradójica implica una modificación de la tarea de la ciencia y la teoría, pues como lo señala Cornelius Borck, siguiendo a Canguilhem, la tarea 
Vivimos pues en una tensión permanente entre la astenia total y el desbordamiento de fuerza. Gracias a esta tensión la enfermedad puede ser asumida como una respuesta creativa del organismo ante cambios en el medio ambiente o ante alteraciones de su normatividad biológica. En este sentido, el organismo alterado tiene que inventar nuevas respuestas para poder así sobrevivir, es decir, crear nuevas normas para encarar las situaciones que le demandan otras dinámicas distintas a las hasta ahora conocidas. Si el individuo biológico no logra emprender estas nuevas normas para las situaciones que ahora lo desafían, se verá limitado en sus posibilidades vitales, ya sea de un modo permanente o temporal.

Según la normatividad biológica analizada por Canguilhem, el ser vivo prefiera la vida a la muerte, la salud a la enfermedad. Por esta razón, su dinamismo vital consiste en seleccionar ${ }^{23}$. Y en este proceso de selección el medio no le es indiferente al individuo. Para realizar sus metas y expectativas vitales, el organismo individual discrimina y selec0ciona ciertas normas o valores de vida. Así, se conserva y se individualiza. En efecto, gracias a su dinamismo vital el individuo puede someterse al medio o instituir su propio medio. No olvidemos que, para la clínica, el origen de la enfermedad «tiene que ser buscado en la experiencia que los hombres tienen de sus relaciones de conjunto con el medio ambiente» (Canguilhem, 2011, 61). La normatividad constitutiva de un individuo biológico no es otra cosa pues que la prolongación de la normatividad ínsita en la vida y, como tal, se trata de una normatividad que comparte con todo ser viviente. En su propia experiencia cada individuo aprehende el dinamismo vital de intercambio entre su normatividad y la normatividad del medio. Por esta razón, en la consideración clínica se debe tener en cuenta la forma como el individuo realiza este intercambio y no simplemente atender a meros datos estadísticos estandarizados y generales. Para Canguilhem, toda diferencia normativa ocurre a nivel de la experiencia vivida individualmente. Esto implica considerar que en toda trama vital se da

propia de la filosofía consiste en hacer complicada las cosas, no sólo para el historiador de la ciencia, sino también para el hombre en general (Borck, 2014, 168). Examinando el papel de la normalidad en la historia del pensamiento biológico, Canguilhelm sostiene de manera reiterada que «la función propia de la filosofía es complicar la existencia del hombre, incluida la existencia del historiador de las ciencias»(CAnguilhem, 2005, 175). Así como Bichat realizó un viraje en la medicina, que implicaba pedirle a la muerte las cuentas de la vida (CANGuilhem, 2009, 166-182), la patología paradójica busca pedirle «a la enfermedad cuentas de la salud»(CAnguilhem, 2011, 230). En esta petición de cuentas es fundamental escuchar nuestra experiencia concreta de la enfermedad y el dolor.

${ }_{23}$ Cuando examinamos el proceso general de la vida, descubrimos que vivir es siempre elegir y omitir. Por ejemplo, «la asimilación es la reducción del alimento, o sea, de lo proporcionado por el medio inerte o viviente, a la sustancia del animal que se nutre, pero también es la manera de tratar indistinta, indiferentemente, lo que se asimila. La diferencia radica entre lo que se retiene y lo que se rechaza. En el hombre hay, por ende, una generalización imposible - el reconocimiento de que todo es diverso- y la generalización inútil: el reconocimiento de que todo es idéntico» (CANGuilhem, 2009, 373). 
un lazo estrecho entre norma vital y variabilidad individual. La delimitación de este lazo es pues la tarea central del trabajo clínico, que siempre remite a la atención de un individuo en un determinado momento y circunstancias en las que se ve envuelto y afectado.

La patología paradójica del hombre normal permite tomar distancia de la concepción ontológica de la enfermedad, que la asume como un opuesto cualitativo a la salud. Se aparta también de la concepción positiva que deriva las afecciones y padecimientos, derivándolos de un estado previo de normalidad estadística $^{24}$. Si la enfermedad se asume como un mal, su terapéutica consistirá en una cierta revalorización de lo acontecido; y si se la concibe como un defecto o un excedente, su tratamiento será entonces el despliegue de una serie de estrategias de compensación (Canguilhem, 2011, 221) ${ }^{25}$. Si, por un lado, el cáncer está adherido, según Mukherjee, a nuestro genoma, de modo tal que expresa una modificación de la estructura básica de regulación de la fisiología del crecimiento, envejecimiento y muerte de un organismo individual, para la patología paradójica, la enfermedad es, por el otro, «aún una norma de vida, pero es una norma inferior en el sentido de que no tolera ninguna desviación de las condiciones en las que vale, puesto que es incapaz de transformarse en otra norma» (Canguilhem, 2011, 139).

En este sentido, un individuo que se siente enfermo revela una estructura individual modificada. La clínica debe, por tanto, poder escuchar al individuo que expresa dicha modificación, sin reducirlo a una mera indicación estadística estandarizada en casos generales. Toda enfermedad del hombre normal es pues siempre la modificación de una uniformidad incorruptible de lo normal. El hombre normal presiente en sí mismo la debacle de su condición, aunque no

24 Gracias a esta distancia podemos pensar que enfermedades como el cáncer no consisten simplemente en una diferencia cualitativa entre huésped y agente, permitiendo así que el paciente que las sufre experimente otra forma de vivir, de percibir el mundo y percibirse a sí mismo. Aunque se diga que entre huésped y agente se da simplemente una diferencia cuantitativa, no se pueden desconocer empero sus efectos cualitativos. Por esta razón, el oncólogo Zajicek señala que «tras décadas de investigación intensiva para determinar las diferencias cualitativas entre tumor y huésped, nada se ha encontrado. Un siglo de investigación tratando de encontrar un único antígeno del tumor ausente en el huésped ha fallado [...] Tumor y huésped solo difieren cuantitativamente. Todas las propiedades del tejido normal están expresadas de manera exagerada en el tumor. Como un demonio o un parásito genuino, un tumor no es un agente externo, son parte integral del huésped» (ZAJICEK, 2001, 244).

${ }_{25}$ Para Gehlen, «el ser humano [...] con su carencia de instintos [...] sería incapaz de vivir. Estas carencias son compensadas gracias a la capacidad que corresponde a la más urgente necesidad: transformar la naturaleza bruta [...] de tal modo que sirva a la vida» (GEHLEN, 1961, 1). Esto implica entonces considerar al hombre no como un triunfador, sino más bien «como un animal que huye de sus defectos compensándolos; [...] el ser humano es el que, al ser físicamente inútil, debe hacer, puede hacer y hace en vez de» (MARQuARD, 2001, 30). Este desplazamiento compensatorio es justamente el movimiento traslaticio acontecido en la metáfora, en la medida en que nos permite encarar la realidad, sin tener que soportarla. 
pueda hacer algo por sí mismo para detener esta catástrofe ${ }^{26}$. En efecto, este hombre se comporta como aquel buen piloto que se sabe capaz de hundir su barco.

Al finalizar el texto de 1963, titulado Nuevas reflexiones relativas a lo normal y lo patológico, Canguilhem apela a la metáfora del naufragio. Esta metáfora es ampliamente examinada también por el filósofo alemán Hans Blumenberg en su antropología metaforológica, para indicar la fragilidad y vulnerabilidad de la existencia humana ${ }^{27}$. Canguilhem apela a esta metáfora para señalar que la paradoja que atraviesa la vida del hombre normal consiste en que «se sabe capaz de hacer zozobrar su cuerpo, pero vive la certidumbre de rechazar esa eventualidad. Tratándose de la enfermedad, el hombre normal es aquel que vive la seguridad de poder impedir el desarrollo en él de aquello que en otro llegaría hasta sus últimas consecuencias»(Canguilhem, 2011, 231). En este sentido, cada uno de nosotros lleva consigo la sombra de la enfermedad.

De igual manera, el oncohematólogo Siddhartha Mukherjee, escuchando atentamente a su paciente Carla Reed, señala que la enfermedad del cáncer es realmente el hundimiento en una nueva normalidad, la del paciente, y «muy posiblemente también sea la nuestra; muy posiblemente estemos, por esencia, destinados a derivar lentamente hacia un final maligno» (Mukherjee, 2014, 549). Esta metáfora del naufragio es tan reveladora de nuestra frágil condición biológica, como pavorosa puede llegar a ser también su comprensión ligera.

Queremos detenernos ahora en la manera en la que Hans Blumenberg emprende la articulación entre metáfora, la experiencia de la enfermedad y

${ }_{26}$ En la epistemología histórica de Canguilhem un papel fundamental lo ocupa la consideración de los monstruos y las catástrofes biológicas, que muestran justamente la emergencia de nuevas formas de normatividad al interior de la vida misma, como señalando que no nos es posible determinar un único modelo estandarizado de lo que consideramos como normal. Antes se consideraba que «el monstruo es un error de la naturaleza que se equivocó de materia. Si bien en la patología molecular de hoy el error engendra más bien el vicio de forma, sigue siendo verdad que los errores bioquímicos hereditarios son considerados como microanomalías, como micromonstruosidades. Y así como cierta cantidad de anomalías morfológicas congénitas son interpretadas como fijación del embrión en un estadio de desarrollo que normalmente debería ser superado, del mismo modo cierta cantidad de errores metabólicos lo son como interrupción o suspensión de una sucesión de reacciones químicas» (CANGUILHEM, 2011, 224). Estas alteraciones no son, empero, ausencia de forma, sino más bien nuevas organizaciones normativas de la vida.

${ }_{27}$ El tema del naufragio es asumido por Blumenberg de manera particular en su bello trabajo de 1979 titulado Naufragio con espectador. Paradigma de una metáfora de la existencia. En este texto el punto de partida de Blumenberg para examinar la paradoja de la existencia humana consiste en reconocer que «el hombre conduce su vida y levanta sus instituciones sobre tierra firme. Sin embargo, prefiere concebir el movimiento de su existencia, en su conjunto, mediante la metafórica de la navegación arriesgada. El repertorio de esta metafórica náutica de la existencia es proteico. Hay costas e islas, puertos y alta mar, arrecifes y tormentas, profundidades y bonanzas, velas y timones, timoneles y tenederos, brújula y navegación astronómica, faros y pilotos. A menudo, la representación de los peligros de alta mar sólo sirve para resaltar la comodidad y la calma, la seguridad y la serenidad del puerto en el que ha de concluir la travesía» (BlumenBerg, 1997a, 9; 1995, 13). 
el dolor, pues consideramos que podemos encontrar aquí nuevos elementos metaforológicos para complementar los ensayos de la patología paradójica del hombre normal. Para dar este paso, es necesario seguir una vez más la divisa metodológica de la investigación clínica de Canguilhem, según la cual «el pathos es quien condiciona al logos» $(2011,160)$. Consideramos que esta divisa está también expresada en la antropología filosófica de Blumenberg.

\section{Metaforología y delegación}

$\mathrm{Al}$ igual que sucede en los casos anteriores, la metáfora en Blumenberg no es un medio de expresión, como ingenuamente se puede llegar a creer. Más bien, es un modo esencial de comprensión de aquellos asuntos que resultan difíciles de asumir de manera temática ${ }^{28}$. Esta forma de comprender la metáfora tiene una cierta semejanza con la idea de Cassirer de la configuración de las formas simbólicas ${ }^{29}$. En efecto, requerimos de una red simbólica para tener una comprensión de nosotros mismos, de lo que nos afecta y del mundo en el cual vivimos. Sin esta acuñación simbólica no logramos darnos un lugar en el

28 En su texto Elementos para una teoría de la inconceptualidad Blumenberg subraya el carácter comprensivo que tiene la metáfora, cuando indica que la metafórica es una «modalidad auténtica de comprensión de conexiones que no pueden circunscribirse al limitado núcleo de la metáfora absoluta. Incluso ésta se definía ante todo por su no disponibilidad a ser sustituida por predicados reales en el mismo plano del lenguaje» (BlumENBERG, 1997a, 87; 1995, 97). Por esta razón, la metáfora es realmente el recurso por excelencia de la metafísica. En este sentido, este recurso se debe a la función de la metáfora como una especie de «iconología de lo abstracto»(Blumenberg, 1997b, 91). De esta manera, Blumenberg reclama que la metáfora tiene un derecho propio frente a los grandes sistemas metafísicos de Occidente. Aquí se asume la metaforología como una cierta modulación del programa kantiano de emprender antes que nada una crítica de la razón pura, esto es, de comprender la metafísica como una cierta ciencia limitada (CARDONA, 2017). Al igual que sucede con esta ciencia en Kant, el trabajo metaforológico de Blumenberg se nos presenta como el desarrollo de una serie de ejercicios metaforológicos nunca terminados de manera sistemática. Monika Bezler señala que «el desarrollo histórico del pensamiento de Blumenberg muestra, por un lado, una absolutización tendencial de la metáfora al servicio de la captación de las condiciones posteriores del mundo de la vida como respaldo a las motivaciones expulsadas de toda teoría» (BEzler, 1991, 232). Esta absolutización resulta paradójica, pues la función de la metáfora no se da a espaldas de la historia y del mundo de la vida en la cual se enmarca y opera. En este sentido, sería imposible una comprensión pura de una metáfora, pues ella no puede ser abstraída de la historicidad en la cual aparece.

${ }_{29} \mathrm{Al}$ contrario de Cassirer, Blumenberg no quiere hacer depender su metaforología de observaciones antropológicas y culturales. Si la antropológica filosófica desarrollada por Cassirer se centra en la idea del animal symbolicum, la comprensión de Blumenberg del hombre no busca construir la idea de un animal metaphoricum que se despliegue en formas múltiples de su ser symbolicum. Esto significa que la metáfora es ella misma metafórica, esto es, un concepto tomado de la retórica para determinadas figuras del discurso que se convierten en una experiencia antropológica fundamental inmersa ya en el mundo de la vida del hombre y que, como tal, se debe asumir como un concepto límite histórico y cultural 
mundo, ya que, gracias a la metáfora, el símbolo y la delegación apartamos de la vista la dolorosa realidad que nos interpela de manera constante.

Si bien con la palabra queremos hacer comprensible lo que nos sucede, con la metáfora intentamos acceder a lo inefable (Blumenberg, 1997a, 95; 1995, 106), ya que permite hacer llevadera la carencia de significación que nos acosa en todo momento. En efecto, no contamos con una red de significación que pueda ofrecer un cumplimiento completo de sentido a todo aquello que nos afecta o acaece. Tan sólo tenemos figuras aisladas que a lo sumo forman un pensamiento metafórico. La metáfora es pues la estrategia más eficiente de compensación de la carencia propia de nuestra forma de vida (Blumenberg, 1997a, 100; 1995, 111), ya que vivimos determinados por la inquietud de la existencia desnuda, esa inquietud que nos revela que «el dolor mora en el tiempo o, mejor dicho, también en el tiempo» (Blumenberg, 2017, 23; 1992, 21).

Para Blumenberg, el símbolo es el «límite de la metáfora» $(2014,116)$. La metáfora y el símbolo explican la realidad por medio de algo distinto. Si la metáfora necesita forzosamente de una referencia asociativa al explicandum, el símbolo, por su parte, remite a algo completamente otro. Esta referencia al explicandum se da como experiencia de comprensión, en la cual nos topamos con algo realmente inconmensurable. En este sentido, el animal metaphoricum se mantiene limitado al ámbito mundovital de las necesidades de su existencia. Una metáfora absoluta ${ }^{30}$ jamás se deja fijar completamente, en la medida en que siempre permanece en ella una resistencia nunca resoluble de modo conceptual. Por esta razón, la metáfora expresa la inconceptualidad (Unbegrifflichkeit) que caracteriza a la comprensión de nuestra existencia, porque «el concepto no puede todo lo que la razón demanda» (Blumenberg, 2007, 11).

Para resaltar la dimensión antropológica del rodeo metafórico, Blumenberg vincula la metáfora con la delegación. Menciona la delegación por primera vez en su famoso texto Trabajo sobre el mito (Blumenberg, 1996a, 28; 2003, 29; 1996a, 599; 2003, 584). La delegación es pues un proceso de enfrentamiento de la realidad a través del nombre y el símbolo o por medio del ritual y las prácticas míticas ${ }^{31}$. Y en Salidas de la caverna introduce la delegación

30 Para Blumenberg, las metáforas son realmente «restos» en el camino del mito al logos. En este sentido, son también los elementos básicos de nuestra comprensión del mundo y, por tanto, son piezas constitutivas del lenguaje filosófico. Estas transferencias no se pueden reducir a la logicidad; "Si fuese posible mostrar que se dan tales "transferencias", transferencias [Übertragungen] que habría que llamar "metáforas absolutas", la fijación y análisis de su función enunciativa, conceptualmente irresoluble, constituiría una pieza esencial de la historia de los conceptos» $(2013,14 ; 2003,44-45)$.

31 El hombre no se expone directamente a la realidad, sino que puede delegar el contacto inmediato con ella a instituciones culturales, es decir, el hombre representa la realidad potencialmente letal por medio de los símbolos o ritos y no como lo proclama la Modernidad ilustrada a partir del concepto y la razón (Pippin, 1999, 101; Nicholls, A./ Heidenreich, F, 2014, 214-227). Un caso particular de esta estrategia lo podemos encontrar en nuestras consideraciones habituales sobre la experiencia del dolor y el sufrimiento humano, tal como lo hemos indicado en este texto a partir del análisis de Ozick, Sontag y Mukherjee. 
como categoría antropológica ${ }^{32}$ en relación directa con las consideraciones psicoanalíticas sobre el sueño y el duelo. La delegación se convierte aquí en una estrategia simbólica de sustitución de lo reprimido, en la medida en que funciona como «el tributo, que el otro, lo otro, acepta de un ser vivo en lugar de su vida misma» (Blumenberg, 1996b, 71; 2004, 64). El rendimiento de esta estrategia consiste en que reemplaza el absolutismo de la realidad que afecta nuestra existencia y que, a menudo, se presenta con crudeza en la experiencia del dolor y la enfermedad. Por esta razón, Blumenberg suele hablar de «técnicas de delegación» (Blumenberg, 1996b, 71; 2004, 64), que presuponen y a la vez posibilitan el trabajo de la distancia ${ }^{33}$.

En este sentido, la delegación es un «artificio para sobrevivir» (Blumenberg, 1997b, 413) o, como lo hemos indicado aquí, un medio de comprensión. Ella posibilita el trato con la realidad, porque pone en el lugar de la experiencia inmediata un gran reemplazo como el símbolo y las metáforas. La delegación es pues una expresión de distancia para compensar la "severidad de la realidad» (Blumenberg, 2003, 237). Solo podemos dominar la realidad genuinamente mortal, en la medida en que apartamos lo extraño a partir de lo que nos es familiar (Blumenberg, 204, 116). Al contrario de lo señalado en 1988 por Susan Sontag ${ }^{34}$, podemos sostener ahora con Blumenberg que las metáforas no matan, sino que más bien, en su movimiento traslaticio ${ }^{35}$, abren posibilidades de vida

32 En su trabajo Goethe zum Beispiel, Blumenberg precisa la dimensión antropológica de la delegación señalando que «entre todas las habilidades que el hombre trae al mundo la más asombrosa de todas es tal vez la delegación. En el sistema de la determinación antropológica ella se relaciona estrechamente con la libertad, siempre que se recuerde tratar este concepto no sólo en el nivel supremo de la espiritualidad» (BLumEnBerg, 1999, 23).

33 En este sentido, la delegación es la respuesta del hombre al requerimiento de la totalidad, en la medida en que reduce su absolutismo. El rendimiento de la delegación es pues una elemental experiencia cultural, en la medida en que es una explicación mítica del mundo en el contexto de un horizonte amplio de interacción del hombre con la realidad. El mito como forma simbólica es delegación. La instancia que delega, esto es, que ofrece finalmente la respuesta, es la razón. Pero el enigma de esta instancia radica en que la razón es justamente «algo que no puede ser delegado» (BlumenBerg, 1996a, 181; 2003, 181).

34 En su ensayo El sida y sus metáforas Sontag señala que en su experiencia reflexiva sobre la enfermedad se convenció de que «las metáforas y los mitos matan. (Por ejemplo, infunden un miedo irracional a las medidas eficaces como la quimioterapia, y fomentan las creencias en métodos totalmente inútiles como las dietas y la psicoterapia). Quería ofrecer a los demás enfermos y a quienes cuidan de ellos un instrumento que disolviera estas metáforas, estas inhibiciones. Esperaba ofrecer a los aterrados de que consultaran a un médico, o cambiaran a un médico incompetente por otro, competente, que fuera capaz de cuidar adecuadamente de ellos. Que deberían considerar el cáncer como una mera enfermedad; muy grave, pero no más que una enfermedad. No una maldición, ni un castigo, ni un motivo de vergüenza. Sin "significado". Y no necesariamente una sentencia de muerte (una mixtificación es: cáncer=muerte)» (SonTAG, 2017, 116).

35 Tomando distancia de Aristóteles, Blumenberg retoma al Kant de la Crítica del juicio, en particular cuando en el parágrafo 59 describe el movimiento traslaticio agenciado en la metáfora, aunque él hable del símbolo, como el procedimiento del transporte de la reflexión: «Kant parte aquí de una intuición básica de que la realidad del concepto sólo se puede exponer 
gracias a su poder comprensor. Aquí lo extraño y amenazante es reemplazado por lo familiar.

El termino delegación proviene inicialmente de los campos de la administración y la política. Pero en Descripción del ser humano Blumenberg amplía su significado para caracterizar el modo peculiar como asumimos las contingencias y penurias de la vida humana ${ }^{36}$. Como función antropológica la delegación tiene un papel fundamental en la experiencia del sufrimiento y la enfermedad. En la medida en que el hombre busca esquivar o apartar de la mirada todo aquello que lo perturba, el movimiento traslaticio de la metáfora se cumple también como un arte de delegación y de distanciamiento de la crudeza inicial de la rea$\operatorname{lidad}^{37}$. Desde los comienzos de la cultura hemos buscado alentar con la palabra al hombre abatido. Somos seres no sólo capaces de dar consuelo, sino también necesitados de él. Recordemos, por ejemplo, que cuando estamos particularmente tensos, tendemos a «la evacuación de la energía emocional acumulada mediante el acto simbólico de la expresión, de la expresión posiblemente como sustituto de acciones de otra índole» (Blumenberg, 2006, 624; 2011, 465).

por medio de intuiciones. Esto, en el caso de los conceptos empíricos, ocurre por medio de ejemplos, en el caso de los conceptos puros del entendimiento por medio de esquemas, en el caso de los conceptos de razón («ideas»), para los que no puede proporcionarse ninguna intuición adecuada, ocurre poniendo bajo el concepto una representación que sólo tiene en común con lo mentado la forma de la reflexión, pero nada que corresponda al contenido» (Blumenberg, 2013, 15; 2003, 45-46). Esta forma es justamente el trabajo traslaticio propio de la metáfora.

36 No es una sorpresa que la metaforología de Blumenberg tenga que ser vista en conexión directa con su antropología (HeidenREIch, 2005). Para Blumenberg, es preciso reconocer que toda antropología está puesta en el horizonte interpretativo de la abundancia o pobreza de significación del ser humano, en la medida en que la pregunta por el modo de ser de su existencia está orientada por la dotación de dicho horizonte. En su famoso texto de 1971 Aproximación antropológica a la actualidad de la retórica, Blumenberg señala que la verdadera autocomprensión humana es, por un lado, siempre una comprensión retórica de sí mismo y que, no obstante, la naturaleza humana sucede, por el otro, en un cierto enmascaramiento metafísico, ya sea como animal o máquina, o en la diferencia o concurrencia con Dios. El hombre sólo se comprende en la distancia de lo que él no es. No sólo su situación, sino también su constitución, es potencialmente metafórica. Por esta razón, la metáfora puede ser asumida como una categoría antropológica. En este sentido, la tesis fundamentalmente antropológica de Blumenberg se desplaza a la referencia metafórica con la realidad, pues la metáfora es una vía de acceso del hombre hacia sí mismo y hacia la realidad (BLumenBerG, 2014, 406).

37 Para Blumenberg, la delegación consiste entonces en la estrategia según la cual el hombre entrega a otro consciente o inconscientemente aquello que por sí mismo no puede asumir o soportar. Se trata entonces de un acto esencialmente intersubjetivo, pues el hombre que delega sus funciones tiene que pensar en cada momento en sí mismo reconociendo su vulnerabilidad y finitud para asumir por sí mismo lo que la crudeza de la realidad le demanda. En este sentido, el arte de la vida que consiste en entregarse a lo simbólico «tiene que poder soportar siempre también la delegación de la propia cosa en la competencia de otro" (Blumenberg, 2003, 237-238). Pero debemos tener en cuenta que solo se puede delegar la respuesta frente a aquello que el individuo experimenta como poderosos, como aquello que puede aplastarlo teniendo en cuenta la debilidad que lo caracteriza. 
No sólo buscamos descargarnos emocionalmente, sino también comunicar a otros el dolor que nos embarga. Ésta es también la función básica de la comunicación de nuestras vivencias y experiencias más íntimas. Aunque esto no pueda cambiar la realidad de lo que nos perturba, puede empero alterar su reflejo en lo más profundo de nuestra alma. En efecto, esta función la cumple la metáfora, ya que por medio de una difusión ficticia (fiktive Diffusion) ${ }^{38}$ «el que sufre comparte su dolor, delega la función que como portador del dolor tiene que ejercer en principio él mismo y el sólo» (Blumenberg, 2006, 625; 2011, 467).

En esta difusión ficticia la palabra, como lo señala Ozick, que «interpreta y descifra el mundo, forjada por el bien de la humanidad, debe luchar contra su propio cuerpo, contra su propia carne y su propia sangre, contra su propia vida. Una célula combate contra la otra. El halo titila, se enciende, fulgura, se enturbia se atenúa» (Ozick, 2016, 56). Y en este atenuar se transfigura la vida.

Las metáforas no matan. Más bien, al abrir la comprensión del mundo y de nosotros mismos, el lenguaje traslaticio de la metáfora nos permite redefinir, sin caer en una vana mistificación, nuestras posibilidades y victorias frente a la experiencia del dolor y la enfermedad, tal como Siddhartha Mukherjee lo sugería en su recorrido por la biografía del cáncer.

\section{BibLIOGRAFÍA}

Aristóteles. (1992). Poética. Madrid: Editorial Gredos.

Bacarlett, M. (2010). Filosofía y enfermedad. Una introducción a la obra de Georges Canguilhem. México: Universidad Autónoma del Estado de México. Miguel Ángel Porrúa.

Betzler, M. (1991). «Ökonomisierung der Geschichte? Überlegungen zur Metaphorologie Hans Blumenbergs». En: Prima Philosophia, 4, (1991), pp. 219-249.

Blumenberg, H. (2017). Die Sorge geht über den Fluß. Frankfurt: Suhrkamp. (La inquietud que atraviesa el río. Ensayo sobre la metáfora. Barcelona: Península. 1992).

Blumenberg, H. (2014). Ästhetische und metaphorologische Schrifften. Asuwahl und

38 En Descripción del ser humano Blumenberg señala la función que tiene la memoria como una especie peculiar de difusión ficticia, en la medida en que es «la disposición a presentizar objetos y experiencias, que no necesitan estar dados en términos de percepción. El recuerdo es una de las formas de la actio per distans» (2006, 583; 2011, 436). En efecto, para poder sobrevivir necesitamos la seguridad de la distancia espacial y temporal, pues sólo así podemos sobreponernos a todo lo que nos afecta tanto en lo exterior como en nuestro interior. Por ejemplo, «un dolor no se puede comunicar objetivamente, tampoco se puede recordar objetivamente. Ya el recuerdo siempre es más simbólico que real. El mecanismo del olvido, precisamente de las sensaciones subjetivas, tiene un buen fundamento biológico. Si las mujeres tuvieran un recuerdo objetivo de los dolores del parto, la humanidad se habría extinguido hace rato. No hay un gran paso de la incapacidad de recordar las emociones más intensas e íntimas al logro supremo de tal depotenciación en el olvido activo, con independencia de todo lo demás que pueda ocasionar el trauma olvidado» (BlumenBerg, 2006, 632; 2011, 471-472). 
Nachwort von Anselm Heverkamp. Frankfurt: Suhrkamp.

Blumenberg, H. (2013). Paradigmen zu einer Metaphorologie. Kommentar von Anselm Haverkamp. Frankfurt: Suhrkamp. (Paradigmas para una metaforología. Madrid: Trotta. 2003).

Blumenberg, H. (2006). Beschreibung des Menschen. Frankfurt: Suhrkamp. (Descripción del ser humano. Buenos Aires: Fondo de Cultura Económica. 2010).

Blumenberg, H. (2007). Theorie der Unbegrifflichkeit. Aus dem Nachlaß herausgegeben von Anselm Haverkamp. Frankfurt: Suhrkamp.

Blumenberg, H. (2003). Zu den Sachen und zurück. Frankfurt: Suhrkamp.

Blumenberg, H. (1999). Goethe zum Beispiel. Frankfurt: Insel.

Blumenberg, H. (1997a). Schiffbruch mit Zuschauer. Paradigma einer Daseinsmetapher. Frankfurt: Suhrkamp. (Naufragio con espectador. Paradigma de una metáfora de la existencia. Madrid: Visor. 1995).

Blumenberg, H. (1997b). Die Vollzähligkeit der Sterne. Frankfurt: Suhrkamp.

Blumenberg, H. (1996a). Arbeit am Mythos. Frankfurt: Suhrkamp. (Trabajo sobre el mito. Barcelona: Paidós. 2003).

Blumenberg, H. (1996b). Höhlenausgänge. Frankfurt: Suhrkamp. (Salidas de caverna. Madrid: Machado Libros. 2004).

Borck, C. (2014). «Begriffene Geschichte. Canguilhem, Blumenberg und die Wissenschaften». En Borck, C. (Ed). Hans Blumenberg beobachtet. Wissenschaft, Technik und Philosophie. Friburgo: Verlag Karl Albert, 168-195.

Canguilhem, G. (2011). Lo normal y lo patológico. México: Siglo veintiuno editores.

Canguilhem, G. (2009). Estudios de historia y de filosofía de las ciencias. Buenos Aires: Amorrortu.

Canguilhem, G. (2005). Ideología y racionalidad en la historia de las ciencias de la vida. Buenos Aires: Amorrortu.

Canguilhem, G. (2004). Escritos sobre la medicina. Buenos Aires: Amorrortu.

Cardona, F. (2017). «La transformación de la metaphysica naturalis en metaforología». En Universitas Philosophica, (68), 39-80.

Dupuis, M. (2014). L'Éthique organisationnelle dans le secteur de la santé. Ressources et limites contextuelles des pratiques soignantes. París: Seli Arslan.

Gadamer, H. (2011). El estado oculto de la salud. Barcelona: Gedisa.

Gehlen, A. (1961). Anthropologische Forschung. Zur Selbstbegegnug und Selbstentdeckung des Menschen. Reinbek: Rowohlt Verlag.

Giroux, E. (2011). Después de Canguilhem: definir la salud y la enfermedad. Bogotá: Universidad Externado de Colombia.

Heidenreich, F. (2005). Mensch und Moderne bei Hans Blumenberg. Múnich: Wilhelm Fink Verlag.

Jünger, E. (1995). Sobre el dolor. Seguido de La movilización total y Fuego y movimiento. Barcelona: TusQuets.

Kant, I. (2010). Crítica de la razón práctica. Madrid: Gredos.

Kant, I. (2009). Crítica de la razón pura. México: Fondo de Cultura Económica.

Kant, I. (2003). El conflicto de las facultades en tres partes (1798). Madrid: Alianza.

Koch, U. (2015). «Was tun mit Metaphern? Überlegungen zur Bedeutung von Metaphern und Metapherntheorie für die Wissenschaftsgeschichte am Beispiel medizinischer Schockmetaphorik». En Berichte zur Wissenschaftsgeschichte, (38), 321-342.

Marquard, O. (2001). Filosofía de la compensación. Escritos sobre antropología filosófica. Barcelona: Paidós.

Morris, D. (1993). La cultura del dolor. Santiago de Chile: Editorial Andrés Bello. 
Moscoso, J. (2011). Historia cultural del dolor. México: Taurus.

Mukherjee. S. (2017). El gen. Una historia personal. Bogotá: Debate.

Mukherjee, S. (2014). El emperador de todos los males. Una biografía del cáncer. Bogotá: Debate.

Nicholls, A./ Heidenreich, F. (2014). «Mythos». En Buch, R./ Weidner, D. (Eds.). Blumenberg lessen. Ein Glossar. Frankfurt: Suhrkamp, 214-227.

Ozick, C. (2016). Metáfora y memoria. Ensayos reunidos. Madrid: Mardulce.

Pelluchon, C. (2013). La autonomía quebrada. Bioética y filosofía. Bogotá: Editorial Universidad El Bosque.

Pippin, R. (1999), «Eine Moderne ohne radikale Entzauberung. Zwischen Logos und Mythos». En Wetz, J./ Timm, H. (Eds.). Die Kunst des Überlebens. Nachdenken über Hans Blumenberg. Frankfurt: Suhrkamp, 99-117).

Redeker, R. (2017). Bienaventurada vejez. México: Fondo de Cultura Económica.

Sontag, S. (2017). La enfermedad y sus metáforas. El sida y sus metáforas. Bogotá: Penguin Random House.

Zajicek, G. (2001). «Cancer and Metaphysics». En Medical Hypotheses, (57), 243-248.

Pontificia Universidad Javeriana

fcardona@javeriana.edu.co

Luis Fernando Cardona SuÁrez

[Artículo aprobado para publicación en enero de 2019] $]^{39}$

39 Este texto, como todos los publicados, fue revisado y actualizado antes de su publicación 